\title{
DINAMIKA MASYARAKAT DI PULAU ARBOREK DALAM MENJAGA KEARIFAN LOKAL
}

\author{
Uswatul Mardliyah \\ Dosen Fakultas ISIPOL Universitas Muhammadiyah Sorong
}

Diterima:5 Januari 2017. Disetujui:10 Februari 2017. Dipublikasikan:1 Maret 2017

\begin{abstract}
ABSTRAK
Pulau Arborek merupakan salah satu kampung pariwisata terbaik yang ada di Kabupaten Raja Ampat.Keindahannya menjadi daya tarik bagi para turis baik asing maupun lokal untuk menikmati keindahan pulau tersebut.Banyaknya pengunjung yang datang kepulau ini memberikan dampak perubahan pada masyarakat setempat, yang mana masyarakat juga sangat menjunjung tinggi nilai-nilai kearifan lokal. Oleh karena itudalam penelitian ini, penulis mencoba membahasdinamika masyarakat nelayan di pulau Arborek dalam menjaga kearifan lokal. Tujuan adalah; untuk mengetahui kearifan lokal, mengetahui kendala kedala yang dihadapi dan upaya yang dilakukan Masyarakat dalam melestarikan kearifan lokal di pulau Arborek Kabupaten Raja Ampat.Metode yang digunakan dalam penelitian ini adalah dengan menggunakan jenis penelitian kualitatif, dengan cara pengumpulan data; observasi, wawancara, dan kepustakaan serta analisa data yang dilakukan secara akurat agar bisa menyajikannya dalam bentuk laporan penelitian yang menjelaskan dinamika masyarakat di pulau Arborek dalam menjaga kearifan lokal.
\end{abstract}

Kata Kunci: Dinamika - Masyarakat - Kearifan Lokal

\section{PENDAHULUAN}

Ada beberapa suku yang mendiami kabupaten Raja Ampat. Penduduk asli Kabupaten Raja Ampat terdiri dari kurang lebih 10 suku adat : yaitu suku Wawiyai (wauyai), suku Kawe, suku Laganyan, suku Ambel (waren), suku Batanta, suku Tepin, suku Fiat, Domu, Waili dan Butlih, suku Moi (moimaya), suku Matbat, suku Misoul, suku Biga, dan suku Biak.Dan maayoritas penduduk berasal dari suku Biak.

Raja Ampat juga dikenal sebagai salah satu tempat wisata di Indonesia yang sangat indah.Salah satu pulau yang jadi tempat wisata di kabupaten raja ampat adalah pulau arborek.Pulau Arborek adalah kampung Pariwisata dan selain itu pulau tersebut pernah menjadi pemenang lomba kebersihan kampung Sepapua Barat pada tahun 2015. Sebuah Perusahaan besar juga sudah ada disna seperti"berfoot conservation" yang hanya terdapat di Bali milik pengusaha Australia yang bernama Simon yang menyediakan fasilitas lengkap untuk para turis asing maupun lokal menjadikannya sebagai tujuan wisata favorit di Raja Ampat. Karena Pulau ini memiliki destinasi wisata terbaik, ini mejadikan Arborek seringkali dikunjungi oleh turis dari berbagai negara, tentunya ini dapat 
mempengaruhi kearifan lokal dari masyarakat di pulau ini, baik budaya ataupun mata pencaharian.Masyarakat kini mulai menekuni profesi baru yaitu usaha yang berhubungan dengan kepariwisataan seperti; membangun Home Stay atau rumah penginapan, perubahan mata pencaharian ini memberikan dampak positif namun jugaberdampak negative bagi masyarakat.Memberi dampak positif karena dapat meningkatkan perekonomian masyarakat lebih baik yang awalnya adalah nelayan. Memberi dampak negative karena membawa kebiasan-kebiasan atau budaya baru seperti; berpakaian terbuka, karna pada masyarakat barat gaya berbusana terbuka bukanlah sesuatu yang aneh. Mereka yang datangminuman beralkohol, suka berhura-hura bahkan menggunakan bahasa asing yang belum pernah didengar oleh masyarakat arborek, ini sangat berpengaruhterhadap nilai-nilai budaya lokal masyarakat Arborek, dimana masyarakat di pulau ini masih berpegang teguh terhadap kearifan lokal yang dimiliki. Hal ini membuat penulis tertarik untuk memilih judul "Dinamika Masyarakat Di Pulau Arborek Dalam Menjaga Kearifan Lokal" untuk diteliti.

\section{METODE PENELITIAN \\ Metode Penelitian}

Jenis penelitian yang di lakukan dalam penelitian ini, adalah penelitian kualitatif dengan pendekatan analisa deskriptif. Metode ini digunakan untuk mengetahui upaya masyarakat di pulau Arborek
Kabupaten Raja Ampat dalam menjaga kearifan lokal.Penulis jg menggunakan teknikberikut:a. pengamatan, b. wawancara, c. teknik pengumpulan data sekunder atau data kepustakaan, teknik ini digunakan dengan maksud mengumpulkan data melalui sumber tertulis seperti buku, majalah, dan dokumen seperti gambaran lokasi penelitian, keadan geografis penduduk dan lain-lain.

\section{Populasi dan Sampel}

Populasi penelitian adalah Masyarakat Arborek, dalam hal ini responden yang dijadikan sampel dalam penelitian adalah sebagian Masyarakat Arborek dan Aparat kampung Pulau Arborek Distrik Meos Mansar Kabupaten Raja Ampat. Sampel penelitian ini adalah; Kepala kampung sebagai tokoh masyarakat di Pulau Arborek, dan asyarakat yang tinggal di Pulau Arborek

\section{Teknik Analisis Data}

Teknik menganalisis data di lakukan dengan sebagai berikut:Merapikan dan melengkapi data yang kurang, apabila data yang diperoleh dari lapangan belum lengkap, harus dilengkapi hingga menjadi data yang lengkap dan akurat.Mereduksi data-data yang sudah terkumpul dan rangkuman sedemikian rupa dengan menonjolkan atau menunjukan hal-hal yang penting kemudian di susun secara sistematis.

\section{HASIL PENELITIAN DAN PEMBAHASAN \\ Kearifan Lokal Masyarakat di Pulau Arborek}


Masyarakat di Pulau Arborek ini masih sangat menjunjung tinggi nilainilai tradisidan juga adat istiadat warisan nenek moyang mereka, baik menyangkut perilaku sehari-hari juga dalam kehidupan bermasyarakat.Berdasarkan hasil wawancara penulis dengan salah satu informan yang merupakan tokoh masyarakat di Pulau Arborek terkaittradisi yang harus ditaati oleh masyarakatdi kampung Arborek, beliau mengatakan bahwa:

"salah satu tradisi yang harus ditaati adalah sasi pantai, yang dibuat oleh tetua kampung. Ini berlaku untuk penduduk asli danjuga pendatang ataupun tamu yang berkunjung”.(Arborek, 11 November 2016)

Tradisi Sasi Pante yang ada di pulau Arborek merupakan larangan yang dibuat oleh tetua di Kampung Arborek untuk tidak mengambil hasil laut di sekitar pantai pulau Arborek, jika ingin menangkap ikan masyarakat harus berada jauh dari pulau untuk memancing. Sasi tersebut biasa kembali di lepas atau masyarakat Pulau Arborek biasa kembali menangkap ikan di sekitar pulau apabila menjelang pelaksanaan hari besar keagamaan ataupun akan dilaksanakannya acara adat seperti acara pernikahan ataupun mendapat izin dari tetua adat.

Masyarakat Nelayan yang tinggal di Pulau Arborek mayoritas beragama Kristen Protestan sehingga hari Minggu merupakan hari dimana mereka melaksanakan ibadah dan pada hari itu tidak boleh ada aktifitas lain yang dilakukan oleh masyarakatnya apalagi kegiatan tersebut tidak berhubungan dengan kegiatan keagamaan, larangan untuk tidak beraktifitas diluar Pulau Arborek sudah berlangsung lama dan merupakan tradisi yang telah diwariskan oleh nenek moyang Masyarakat yang tinggal di Pulau Arborek secara turun temurun. Masyarakat yang tinggal di Pulau Arborek percaya bahwa apabila tradisi ini dilanggar maka mereka yang melanggar akan ditimpah musibah selain itu akan dipandang buruk oleh masyarakat lain yang tinggal di Pulau Arborek.

Makan bersama yang dilakukan oleh masyarakat yang tinggal di Pulau Arborek selain merupakan tradisi yang diwariskan oleh nenek moyang mereka untuk mengsyukuri nikmat yang diberikan oleh tuhan juga merupakan wadah dalam masyarakat untuk menyelesaikan setiap permasalahan yang pernah terjadi Selain itu karena dalam proses pelaksanaan tradisi ini yang cukup unik karena penyajian makanan harus diletakan di halaman rumah sehingga menjadikan daya tarik tersendiri untuk turis yang berkunjung di Pulau Arborek mengingat Pulau tersebut merupakan Kampung Pariwisata. Tradisi-tradisi tersebutlah yang merupakan nilai kearifan lokal dari Masyarakat Nelayan Tradisional yang tinggal di Pulau Arborek Distrik Meos Mansar Kabupaten Raja Ampat dan masih dipegang teguh oleh Masyarakat Nelayan yang tinggal di Pulau Arborek hingga saat ini. 


\section{Kendala Yang Dihadapi Oleh Masyarakat Nelayan Tradisional Dalam Menjaga Kelestarian Kearifan Lokal Di Pulau Arborek}

Berdasarkan hasil wawancara penulis dengan seorang informan yang merupakan Kepala Kampung di Pulau Arborek terkait yang menjadi kendala yang dirasakan oleh Masyarakat di Pulau Arborek dalam upaya melestarikan kearifan lokal masyarakat, beliau mengatakan bahwa:

"Yang menjadi kendala dalam upaya kami melestarikan kearifan lokal masyarakat disini adalah era modernisasi yang mulai dirasakan oleh anak-anak muda dikampung kami, karena saat ini kebanyakan dari anakanak muda bersekolah di Kota baik itu di Kota Sorong maupun di Kota lain sekitar Papua bahkan tidak sedikit anak-anak kami mendapatkan Beasiswa dari Pemerintah Raja Ampat untuk melanjutkan sekolah di Jakarta sehingga mereka tidak lagi terlalu peduli dengan tradisi-tradisi di kampung, justru lebih tertarik untuk ikut bertingkahlaku seperti kebanyakan anak-anak muda yang tinggal di Kota dan menganggap tradisi kami sebagai suatu hal yang ketinggalan jaman untuk diterapkan dalam keseharian mereka. Selain itu hal lain yang menjadi kendala dalam upaya melestarikan apa yang menjadi tradisi di Kampung kami adalah banyaknya turis asing yang berkunjung maupun menginap dalam waktu yang lama di kampung Arborek ini, baik turis dari luar negri ataupun pengunjung dari dalam negri tentunya dengan gaya hidup mereka yang jauh berbeda dengan masyarakat asli disini, dan masyarakat arborek menganggap gaya hidup orang asing lebih baik daripada gaya hidup masyarakat asli disini sehingga mereka tertarik dan menerapkan gaya hidup tersebut dalam kehidupan sehari-hari mereka". (Arborek 11 November 2016).

Kendala dalam melestarikan kearifan lokal ini pengaruh masuknya era modernisasi kedalam kehidupan masyarakat Pulau Arborek.Banyaknya nilai dan budaya masyarakat yang mengalami perubahan menyebabkan kearifan lokal yang tumbuh dan berkembang didalam masyarakat menjadi terkikis. Misalnya seperti yang terjadi padakehidupan masyarakat Pulau Arborek yang mulai mengikuti gaya hidup masyarakat kota maupun pengunjung yang datang di Pulau Arborek yang tadinya menjujung tinggi nilai-nilai tradisi kini mulai menganggap tradisi sebagai suatu hal yang ketinggalan jaman.

Selain itu juga, hal ini mulai dirasakan oleh Masyarakat Nelayan yang tinggal di Pulau Arborek Kabupaten Raja Ampat seperti yang dikatakan oleh informan berikut:

"Selain itu kendala yang paling berat dalam usaha kami melestarikan kearifan lokal pada Masyarakat Nelayan di 
Pulau Arborek ini adalah, semenjak kampung kami menjadi Kampung Pulau pariwisata dan banyak turis yang berminat untuk berkunjung di Pulau kami ini maka, sebagian besar masyarakat yang tadinya berprofesi sebagai Nelayan beralih profesi ke pekerjaan yang berhubungan dengan kepariwisataan seperti membangun Home Stay untuk penginapan para turis dan mebuat kerajinan untuk dijual ke para turis sebagai cendra mata, sehingga kehidupan bernelayan itu saat ini hanya sebagai pekerjaan sampingan saja bukan lagi sebagai pekerjaan pokok kami mengingat penghasilan masyarakat disini lebih besar apabila mengambil pekerjaan yang berhubungan dengan kepariwisataan dibandingkan dengan hidup sebagai nelayan." (Arborek, 11 November 2016).

Dari hasil wawancara penulis dengan narasumber diatas mengenai Kendala-kendala yang dihadapi oleh Masyarakat Nelayan Tradisional, dalam upaya mereka melestarikan kearifan lokal, yaitu kehidupan yang lebih moderen karena masuknya budaya luar yang dibawa oleh para pengunjung yang berwisata di Pulau Arborek.Masyarakat Nelayan Pulau Arborek sendiri yang juga mulai mengenal dunia luar seperti kehidupan Kota yang tentunya lebih moderen sehingga tidak sedikit dari Masyarakat
Arborek menganggap tradisi merupakan suatu yang ketinggalan jaman. Selain itu, Pengaruh kawasan pariwisata di Pulau Arborek menjadikan Masyarakat meninggalkan profesi mereka sebagai Nelayan dan berkecimpung ke profesi yang berhubungan dengan kepariwisataan, profesi baru ini tentunya lebih baik, sehingga kegiatan bernelayan dianggap hanya sebagai sampingan dalam kehidupan mereka.

\section{Upaya-upaya Yang Dilakukan Masyarakat Nelayan Tradisional Dalam Melestarikan Kearifan Lokal di Pulau Arborek}

Akan tetapi masalah tersebut tidak sedikitpun meruntuhkan semangat dari para tetua adat maupun tokoh masyarakatyang terus berupaya agar tetap melestarikan kearifan lokal yang merupakan identitas dari Masyarakat Nelayan Tradisional yang tinggal di Pulau Arborek.Seperti hasil wawancara penulis dengan informan yang merupakan Kepala Kampung di Pulau Arborek sebagai berikut:

"Dalam upaya kami agar nilainilai kearifan lokal pada Masyarakat Nelayan yang tinggal di Pulau Arborek ini tetap terjaga, kami memberlakukan sетиa aturan adat agar ditaati oleh seтиa orang yang ada di Pulau Arborek ini baik itu penduduk asli di Pulau Arborek ini ataupun para pendatang yang menetap tinggal disini bahkan pengunjung pun diharuskan untuk taat terhadap seтиa aturan adat kami tanpa 
memandang apa agama mereka dan dari mana asal mereka, kami bersama toko-toko adat disini akan memberikan denda adat terhadap siapa saja yang melanggar adat dan tradisi kami, bahkan kami tidak segansegan mengusir siapa saja yang melanggar adat dari kampunng kami". (Arborek, 11 November 2016).

Para tokoh masyarakat dan tokoh adat tegas terhadap orang-orang yang melanggar adat dan tradisi yang ada dalam Masyarakat Nelayan yang tinggal di Pulau Arborek.Tindakan tegas tesebut merupakan tindakan yang ampuh dalam upaya melestarikan kearifan lokal serta menjaga nilai-nilai budaya yang sifatnya tradisional dalam kehidupan Masyarakat Nelayan Tradisional di Pulau Arborek sehingga sampai saat inipun masyarakat di Pulau arborek masi menjunjung tinggi tradisi dan budaya mereka yang merupakan kearifan lokal dari Masyarakat Nelayan Tradisional yang tinggal di Pulau Arborek Kabupaten Raja Ampat.

\section{KESIMPULAN DAN SARAN Kesimpulan}

Berdasarankan hasil penelitian diatas maka penulis menyimpulkan sebagai berikut:

1. Masyarakat Nelayan Tradisional yang tinggal di pulau Arborek, memiliki tradisi atau adat budaya sebagai kearifan lokal yang perlu dilestarikan, seperti tradisi sasi pante, tradisi makan bersama dan larangan untuk tidak meninggalkan pulau Arborek pada hari minggu.

2. Masyarakat nelayan tradisional yang tinggal di pulau Arborek mulai dipengaruhi gaya hidup baru, baik itu karena masyarakat Arborek telah mengenal kehidupan masyarakat perkotaan maupun pengaruh dari banyaknya turis asing dan turis lokal yang berkunjungdengan beragam budaya yang lebih maju daripada budaya yang dimiliki oleh masyarakat nelayan.

3. Dalam upaya melestarikan kearifan lokal padamasyarakat nelayan tradisional, para tokoh adat memberlakukan tradisi mereka kepada siapa saja yang ada di Pulau Arborek, baik itu masyarakat asli maupun masyarakat pendatang atau bahkan turis yang berkunjung harus mentaati norma-norma adat atau tradisi yang berlaku. Apabila ada yang melanggar tradisi yang berlaku tokoh adat akan memberikan hukuman sesuai hukum adat .

\section{Saran}

1. Masyarakat nelayan tradisional yang tinggal di pulau Arborek sebaiknya terus menjaga kelestarian kearifan lokal baik itu berupa adat maupun tradisi tanpa terpengaruh oleh banyaknnya budaya dan tradisi lain yang dibawah oleh turis yang berkunjung di pulau pariwisata Arborek.

2. Meskipun masyarakat nelayan tradisional menerapkan gaya 
hidup yang lebih moderen dalam kehidupan mereka, namun sebaiknya tidak meninggalkan nilai-nilai adat dan tradisi yang telah diwariskan oleh para pendahulu mereka.

3. Ketegasan tokoh adat dalam memberikan sangsi atau memberikan hukum adat kepada para pelanggar adat dan tradisi di pulau Arborek sebaiknya terus di pertahankan demi menjaga kearifan lokal dalam kehidupan masyarakat nelayan tradisional di pulau Arborek Distrik Meos Mansar Kabupaten Raja Ampat.

\section{DAFTAR PUSTAKA}

Azwar, Saifudin, MA,1998Metode

Penelitian. Pustaka Belajar Celeban Timur UH III/548, Yogyakarta.

Bayu Sujaninggrat. 2001, Nelayan dan Laut, PT Karya Ilmu, Surabaya.

Koentjaraningrat.1981, MetodeMetode Penelitian

Masyarakat, PT Gramedia, Jakarta.

Kusnadi.2000. Nelayan Strategi Adaptasi dan Jaringan Sosial.Humaniora Utama Press. Bandung
Muliyana, Deddy, DR, M.A.2003, Metodologi Penelitian

Kualitatif, PT Remaja Rosdakarya, Bandung.

Mulyadi, 2007.Ekonomi Kelautan.PT RajaGrafindo Persada. Jakarta

Mustopo. M.Habib. 1984, Ilmu Budaya Dasar,Usaha Nasional, Surabaya.

Raharjo, M. Dawan. 2006, Mепијu Indonesia Sejahtera, Pustaka LP3ES. Jakarta.

Sahadily, Hassan. 1993, Sosiologi Untuk Masyarakat Indonesia, PT Rineka Cipta, Jakarta.

Soekanto, Soerjono. 2002. Sosiologi Suatu Pengantar.Raja Grafindo Persada, Jakarta.

Soekanto, Soerjono. 2002. Sosiologi

Suatu Pengantar. Raja Grafindo Persada, Jakarta.

Soetarjo, K. 1988, Masyarakat Maritim, Balai Pustaka, Jakarta.

Soetomo, 2008, Masalah Sosial dan Upaya

Pemecahannya.Pustaka Belajar, Yogyakarta.

Widodo,J dan Suadi. 2006. Pengelolaan Sumberdaya Perikanan Laut, Gadjah Mada University

Press. 